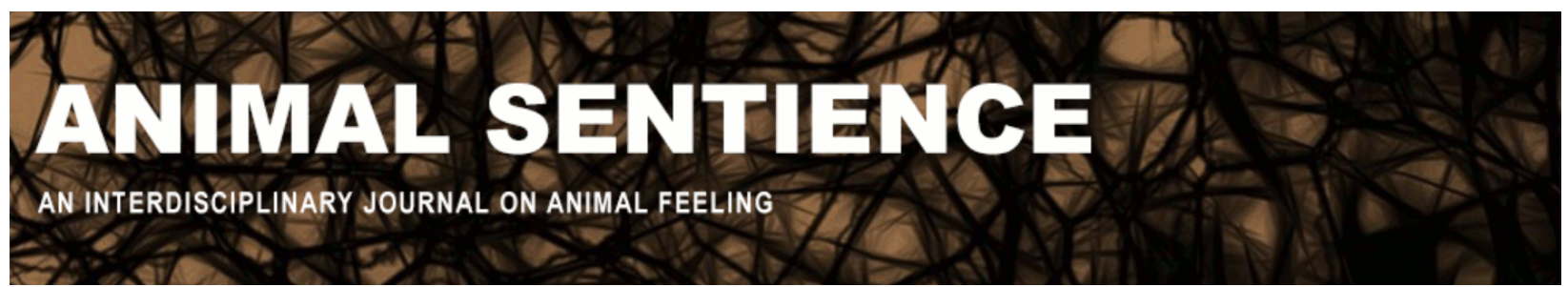

Wintner, Robert (2016) Reef society and the tyranny of data. Animal Sentience $8(2)$

DOI: $10.51291 / 2377-7478.1184$

Date of submission: 2016-12-14

Date of acceptance: 2016-12-26

(c)

This article has appeared in the journal Animal

Sentience, a peer-reviewed journal on animal

cognition and feeling. It has been made open access,

free for all, by WellBeing International and deposited

in the WBI Studies Repository. For more information,

please contact

wbisr-info@wellbeingintl.org.

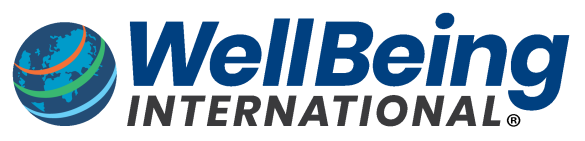

SOLUTIONS FOR PEOPLE, ANIMALS AND ENVIRONMENT 


\title{
Reef society and the tyranny of data
}

Commentary on Balcombe on Fish Knows

\section{Robert Wintner \\ Executive Director, Snorkel Bob Foundation, Hawaii}

\begin{abstract}
Modern science now approaches divergent processes in many areas, including health assessments of marine eco-systems and social aspects of marine species. Scientific data have long enjoyed a reputation for objectivity but incidents of science-for-hire, data spinning/skewing and political jading are more frequent than ever. In the field of reef creature sensitivity, technical treatises can "logically" explain away what a person of average education can clearly observe on any given reef. Western medicine discounted anecdotal evidence of any cure outside the $4 \%$ margin of error until those cures demanded attention and in some cases application. Modern science must now enter an age of practical truth, with data presented, interpreted and peer-reviewed in a common-sense context without regard for political or commercial expediency. A wealth of empirical content combined with credible observations and even a dose of empathy for social order in gill-breathing species makes Balcombe's new book a welcome contribution.
\end{abstract}

Robert Wintner is Executive Director of The Snorkel Bob Foundation, dedicated to defense of reef habitat and species around the world.

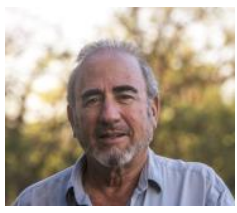
http://snorkelbob.com/sbfoundation-mission/

In my experience, a fish may engage a regular visitor socially. The nonets, hooks or spears caveat applies. Friendship with a peacock razor wrasse seemed unlikely; he shied at first. Caution may be common to the species, but, as science shows (Gosling \& John 1999), individuals don't always show "common" characteristics. On subsequent visits Razorboy came closer and within sniffing distance. In time he rushed over on initial descent, recognizing my wetsuit, camera or body language. Razorboy was a datum.

Kukla was a casual acquaintance in passing who eventually became a friend. He's an elderly yellow-margin moray, who cruised alongside one 
morning, casual as a dive buddy. Some moray species are known for symbiotic hunting (Vail et al. 2014), but we hunted only good camera angles. He nevertheless showed up often after that, sometimes emerging from his burrow in recognition, savoring the photo op. Kukla was another datum.

Are Razorboy and Kukla aberrations to explain away? Were they merely intrigued by reflections of self in the flat port - another enticing possibility (Ari \& D'Agostino 2016)?

Anecdotal evidence tends to be dismissed if it is not statistically demonstrated, or if it implies that other species may have human traits we deem unlikely to be shared by others. After all, fish are cold and slimy and wrapped in newspaper. For ages, the word "fish" has been paired most often with chips. But observant reef visitors will accumulate data on fish society and behavior outside common experience above the surface.

Holding on to a thirty-foot bottom in four knots of current at the notorious Blue Corner in Palau, I wanted to look to either side, but turning my head would have ripped my mask from my face. Letting go granted sudden peace - no friction. The current sped along as several sharks came in, not hunting but schooling. Nobody was threatened, and aiming to either side made for shark family portraits.

The overriding and often ignored truth seems evident to those with first-hand experience - that is, direct contact with the subject. If a fish behaves with increasing trust and friendship - with visible enthusiasm on seeing a familiar, non-threatening marine mammal - then that behavior exists and is predictable. It happens on any reef and especially among reef creatures visited regularly. Notable - and notorious - are stubborn denials of the existence of reef society or fishy friendship or any interspecies communion that defies quantification - or runs counter to entrenched consumer demand. But false conclusions are losing traction in the current, and having their masks ripped off. Dr. Brian Key (2016) of Queensland misses the forest for the trees on the subject of pain and what a fish feels: "Only humans can report feeling pain."

That premise is based on the notion that fish don't feel pain because they are interpreted as ill-equipped neurally to do so. Moreover, the premise proceeds, fish can't verbalize their pain; and so a theory hits the road to Kamakura on two errors.

Abstract jargon begins with: "The thesis proposed here is based on the bioengineering principle that structure determines function" (Key 2016). While the proponent is careful to keep both feet in bounds on the 
logical playing field, he provides no experiential data from the reef world. "Basic functional homologies can be mapped to structural homologies across a broad spectrum of vertebrate species" (Key 2016, abstract). This may be true, but extrapolation is a stretch, just as "common" characteristics don't apply to all individuals. Highfalutin language goes to boilerplate on "... olfaction depends on olfactory glomeruli in the olfactory bulbs of the forebrain, visual orientation responses depend on the laminated optic tectum in the midbrain, and locomotion depends on pattern generators in the spinal cord throughout vertebrate phylogeny, from fish to humans" (Key 2016).

Deduction goes deep in this hinterland, concluding that fish lack the requisite neurocytoarchitecture, microcircuitry, and structural connectivity for feeling pain. Such arguments may sound defensible on paper, but practically they are wrong.

What a Fish Feels (Balcombe 2016 a,b), although well stocked with science, plays more to the real world of experience and observation. Balcombe's treatise on piscine sensitivity has found an appreciative audience, eager for attitudinal change. Some of that readership may have preconceived ideals at the opposite extreme from Key's because collective consciousness is changing, opening the collective mind to intelligence, insight and communicative skills that may not be exclusive to humanity.

Reef creatures visibly enjoy touch when a cleaner wrasse or goby or any herbivore conducts a grooming session. Cleaners pause to caress clients (Bshary \& Würth 2001), whose color changes, fins and gills flare, relaxation and bliss clearly evident. Reef creatures demonstrate enjoyment in grooming, which is a feeling, in essence the opposite of pain. Human touch can compromise their protective coating, so reef creatures mostly avoid touching people (although, tellingly, some can't resist approaching trusted divers to be petted, see Balcombe 2016). That's not pain avoidance but survival instinct. So where do fish feel pain?

Pain is visible in a fish on a hook or in a net. Anyone dislodging a hook from a fish may hear "verbalization" from that fish. Dissatisfaction is the presumed content of that verbalization. At any rate, the fish wants off or out. Apparent anguish might not reflect pain but fear of imminent death, an instinct separate from pain. Empirically speaking, however, science-based sophistry can ignore simple truth - truth beyond the reach of elaborate constructs or lengthy data-compilations. 
Skeptics about this should make friends with a fish. Swim benignly and respectfully in their domain. Or, if you are mean-spirited, take a needle along on a visit. Poke the fish with the needle when it swims or hovers near. Observable in all data sets will be (1) pain, (2) anger and (3) probably the end of friendship.

Friends don't do that, which recalls a radio interview from California and a philosophical question from a local dharma group: Can a fish have a soul? Sorry, but I laughed at the self-absorbed nature of the question and suggested this revision, to better avoid anthropomorphic bias: Can a fish be a friend of mine? Just look. Surely the naysayer will point out that friendship is equally anthro, which is equally biased and leads to the follow-up question: Can species other than humans have friends?

Alas, like Brexit votes and American presidential elections these days, modern science has divergent currents. An example of an archaic application of data that defaults to political need is the state of Hawaii's Department of Land \& Natural Resources, favoring security and expedience for commercial objectives over plain common sense. Just as big tobacco "proved" there was no link between smoking and lung cancer, and as some scientists deny climate change, so too the state of Hawaii follows a rigid policy of "sustainable commercial extraction." Carte blanche reef creature extraction is spuriously based on authoritative data. No species are off limits. Some key collectors in the state data industry, even when their findings seem slanted, are deemed credible because of their university degrees and state employment. That struggle reveals yet again the disjunction between objectivity and agenda.

Similarly, state policy is still stuck on two scientific guidelines in reef assessment: (1) transect grid monitoring, in which each one-meter square is numbered and assessed, possibly over time, and (2) fish counts.

With no scientific credentials, a frequent reef visitor can still provide compelling evidence through common sense, having thrived in Hawaii tourism for decades. With the highest small-business attrition in the nation, Hawaii is a business reef of significant hazard. A reef symposium roster a few years ago listed thirty PhD speakers and one snorkel executive known for survival instinct (me). I presented a third category of reef health and hazard assessment for habitat and species. This simple procedure is somewhat removed from scientific parameters and constraints - from the tyrannies of data, including money, time, political jading, job security, career advancement, self-aggrandizement, and of 
course error: (3) Open your eyes on a reef, look, and see. Only then can you choose to believe - or revert to data.

\section{References}

Ari, C., \& D'Agostino, D. P. (2016) Contingency checking and self-directed behaviors in giant manta rays: Do elasmobranchs have selfawareness? Journal of Ethology, 34, 167-174. doi:10.1007/s10164$\underline{016-0462-z}$

Balcombe, J. (2016a) What a Fish Knows: The Inner Lives of Our Underwater Cousins. New York: Scientific American/Farrar, Straus and Giroux.

Balcombe, J. (2016b) In praise of fishes: Précis of What a fish knows (Balcombe 2016). Animal Sentience 2016.095.

Bshary, R., \& Würth, M. (2001) Cleaner fish Labroides dimidiatus manipulate client reef fish by providing tactile stimulation. Proceedings of the Royal Society of London B, 268, 1495-1501.

Gosling, S. D., \& John, O. P. (1999) Personality dimensions in non-human animals: A cross-species review. Current Directions in Psychological Science, 8, 69-75.

Key, B. (2016) Why fish do not feel pain. Animal Sentience 2016.003.

Vail, A. L., Manica, A., \& Bshary, R. (2014) Fish choose appropriately when and with whom to collaborate. Current Biology, 24, R791-793. http://dx.doi.org/10.1016/j.cub.2014.07.033 